\title{
Effect of Hf Additions to Pt Aluminide Bond Coats on EB-PVD TBC Life
}

\author{
James Nesbitt, Ben Nagaraj* and Jeffrey Williams* \\ NASA Glenn Research Center \\ Cleveland, $\mathrm{OH} 44135$ \\ ${ }^{*}$ General Electric Aircraft Engines \\ Cincinnati, OH 45215
}

\begin{abstract}
Small $\mathrm{Hf}$ additions were incorporated into a $\mathrm{Pt}$ aluminide coating during chemical vapor deposition (CVD) on single crystal RENÉ N5 substrates. Standard yttria-stabilized zirconia top coats were subsequently deposited onto the coated substrates by electron beam-physical vapor deposition (EB-PVD). The coated substrates underwent accelerated thermal cycle testing in a furnace at a temperature in excess of $1121^{\circ} \mathrm{C}\left(2050^{\circ} \mathrm{F}\right)(45$ minute hot exposure, 15 minute cool to approximately $121^{\circ} \mathrm{C}\left(250^{\circ} \mathrm{F}\right)$ ) until the thermal barrier coating (TBC) failed by spallation. Incorporating $\mathrm{Hf}$ in the bond coat increased the $\mathrm{TBC}$ life by slightly more than three times that of a baseline coating without added Hf. Scanning electron microscopy of the spalled surfaces indicated that the presence of the $\mathrm{Hf}$ increased the adherence of the thermally grown alumina to the $\mathrm{Pt}$ aluminide bond coat. The presence of oxide pegs growing into the coating from the thermally grown alumina may also partially account for the improved TBC life by creating a near-surface layer with a graded coefficient of thermal expansion.
\end{abstract}




\section{Introduction}

Thermal barrier coatings (TBC's) are commonly applied to Ni-based turbine components to either reduce component temperatures and thereby extend component life, or allow higher operating temperatures yielding higher engine efficiencies [1-3]. TBC's provide thermal protection via an outer ceramic layer usually consisting of $\mathrm{ZrO}_{2}-(6-8 w t . \%) \mathrm{Y}_{2} \mathrm{O}_{3}$ (referred to as YSZ for yttria stabilized zirconia). This ceramic layer, or top coat, is normally applied by either plasma spraying or by electron beam-physical vapor deposition (EB-PVD) $[2,4]$. Typical thicknesses of this ceramic layer for aero gas turbines are between 125-250 microns. The ceramic top coat is deposited over a metallic bond coat. The bond coat is usually either an MCrAlY coating (where M refers to $\mathrm{Ni}$ or $\mathrm{Co}$, or a combination of the two) or a $\mathrm{Ni}$ aluminide coating. More recently, the incorporation of $\mathrm{Pt}$ in the aluminide to form the so-called Pt-modified nickel aluminides have been increasingly used as bond coats for TBC's. Pt-modified aluminides are produced by electroplating a thin ( $\sim-10$ micron) Pt layer on the component prior to the aluminizing treatment. This aluminizing treatment is most commonly performed by chemical vapor deposition (CVD) processes [5]. This paper will deal solely with Pt-modified Ni aluminide bond coats and EB-PVD YSZ top coat TBC's.

At operating temperatures, oxygen in the combustion gases easily penetrates the YSZ top coat and selectively oxidizes the $\mathrm{Al}$ in the bond coat to form a thin alumina (generally $\alpha-\mathrm{Al}_{2} \mathrm{O}_{3}$ ) scale between the bond coat and top coat. This alumina layer, commonly referred to as the TGO layer (thermally grown oxide), grows sufficiently slow so as to provide oxidation protection for the component. The bond coat is slowly depleted of $\mathrm{Al}$ by the continued growth of the TGO but also by interdiffusion of $\mathrm{Al}$ into the substrate [6]. Continued oxidation and growth of the TGO eventually results in spallation of the top coat (i.e., TBC failure) [1,7-9]. For EB-PVD YSZ top coats on aluminide bond coats, the cracking and delamination of the top coat typically occurs between the TGO and bond coat with the TGO adhering to the bottom of the YSZ top coat $[1,2]$. Hence, improving the adherence of the TGO to the bond coat is expected to extend the time until TBC failure (i.e., increase the TBC "life").

Two techniques have been used to improve the adhesion of thermally grown alumina scales to high temperature alloys and coatings. First, studies over the past two decades have shown that incorporation of reactive elements (e.g., $\mathrm{Y}, \mathrm{Zr}$ or Hf) in a coating improves the adherence of the protective alumina scale which grows during elevated temperature exposures [10]. Recent work has also begun to examine additions of $\mathrm{Hf}$ to aluminide and Pt-modified coatings [11]. Secondly, desulfurizing to extremely low $\mathrm{S}$ levels (i.e., less than 1 ppmw $\mathrm{S}$ ) has also been shown to significantly improve the adherence of the alumina scale on both coating alloys and superalloys [12-14]. The present work deals with the former technique of increasing adherence by incorporation of a reactive element. More specifically, the effect of $\mathrm{Hf}$ additions to CVD Ptmodified aluminide bond coats on the cyclic furnace life of EB-PVD TBC's was evaluated. Coating morphologies and microstructures, before and after testing, were examined. An explanation for the beneficial effect of the Hf addition on the TBC life, based on oxide scale morphologies, is suggested.

\section{Procedure}

The substrate material used in this study was the Ni-base superalloy RENÉ $N 5^{*}$. The nominal composition of RENÉ N5 is Ni-7.5Co-7.0Cr-6.5Ta-6.2Al-5.0W-3.0Re-1.5Mo-0.16Hf-0.02Ti$0.05 \mathrm{C}$. Single crystal slabs were machined into $1 \times 0.125$ inch disks. One side of the disk was

\footnotetext{
"RENÉ is a trademark of the General Electric Company, Fairfield, CT.
} 
ground to remove the EDM recast layer. Samples were vapor honed to remove the grinding marks

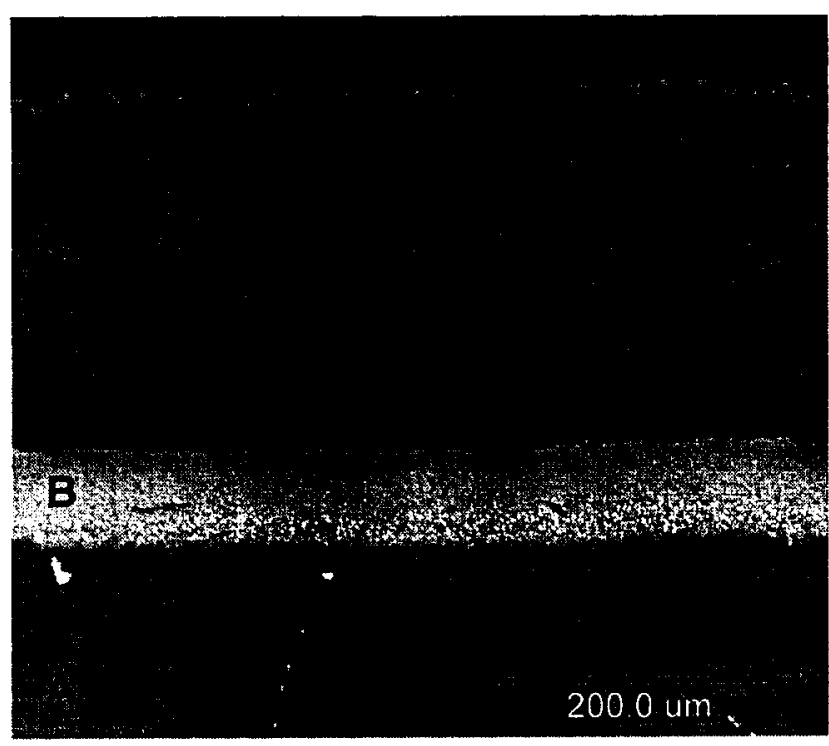

Figure 1 BSE SEM micrographs of a typical Ptmodified aluminide bond coat $(B)$ on a superalloy substrate (A) and an EB-PVD zirconiayttria top coat (C). and produce a uniform matte finish. The disks were electroplated with $\mathrm{Pt}$ and given a short diffusion anneal at General Electric Aircraft Engines, (GEAE, Cincinnati, $\mathrm{OH}$ ). The Pt-plated disks were then sent to a commercial coating vendor for both baseline $\mathrm{Pt}$ aluminide and $\mathrm{Hf}$-modified $\mathrm{Pt}$ aluminide coating formation by a CVD process. After aluminide coating, a small section of the disk was cut off, mounted and polished to record the initial coating morphology and microstructure. Initial microstructures and surface morphologies were examined by scanning electron microscopy (SEM) with energy dispersive spectroscopy (EDS) and optical microscopy (OM) and concentration profiles were measured across the coating by electron microprobe (EMP). The remaining disk portion received an alumina grit blast prior to deposition of a 7YSZ top coat by EB-PVD at GEAE. The microstructure of a typical TBC coating with a Pt-aluminide bond coat and EB-PVD top coat is shown in Figure 1. The bond coat is brighter than the substrate in this backscatter (BSE: backscatter electron image) SEM micrograph due to the Pt within the coating.

Coated disks underwent accelerated thermal cycle testing in a furnace at a temperature in excess of $1121^{\circ} \mathrm{C}\left(2050^{\circ} \mathrm{F}\right) .^{\dagger}$ Each cycle consisted of an approximate 9 minute heatup, 45 minute exposure at temperature followed by a cooling period of 15 minutes to approximately $121^{\circ} \mathrm{C}\left(250^{\circ} \mathrm{F}\right)$. The samples were visually inspected for top coat spallation every 20 cycles and removed from the furnace after approximately $20-40 \%$ minimum loss of the ceramic top coat. Surface morphology of tested disks was examined by SEM prior to being sectioned and mounted. Cross sections of mounted pieces were also examined by OM and SEM/EDS. Pre- and post-test mounted and polished microstructures were often swab etched using a 33 methanol, $33 \mathrm{HNO}_{3}, 33 \mathrm{H}_{2} \mathrm{O}, 1 \mathrm{Hf}$ etchant or 33 ascetic acid, $33 \mathrm{HNO}_{3}, 33 \mathrm{H}_{2} \mathrm{O}$, $1 \mathrm{Hf}$ etchant. In the following sections, the two coatings will be referred to as the baseline (without Hf) or the Hf-containing coating.

\section{Results}

\section{Pretest Coating Morphology and Microstructure}

The surface morphology of the baseline and the Hf-containing coating is shown in Figure 2. As observed elsewhere $[8,12,15-17]$, ridges outlining the coating grains form on the surface of the coatings after the aluminizing treatment. The grain size for both coatings is similar (generally 50150 microns) with that of the baseline coating appearing slightly larger than that for the Hfmodified coating. The width of the ridges appears wider for the Hf-containing coating whereas the region between the ridges of the baseline coating is noticeably smoother and flatter. Figure 3 shows that there is a subscale network both on and between the ridges on the Hf-containing coating.

\footnotetext{
${ }^{\dagger}$ This data is subject to limited exclusive rights under NASA contract NAS3-26385.
} 

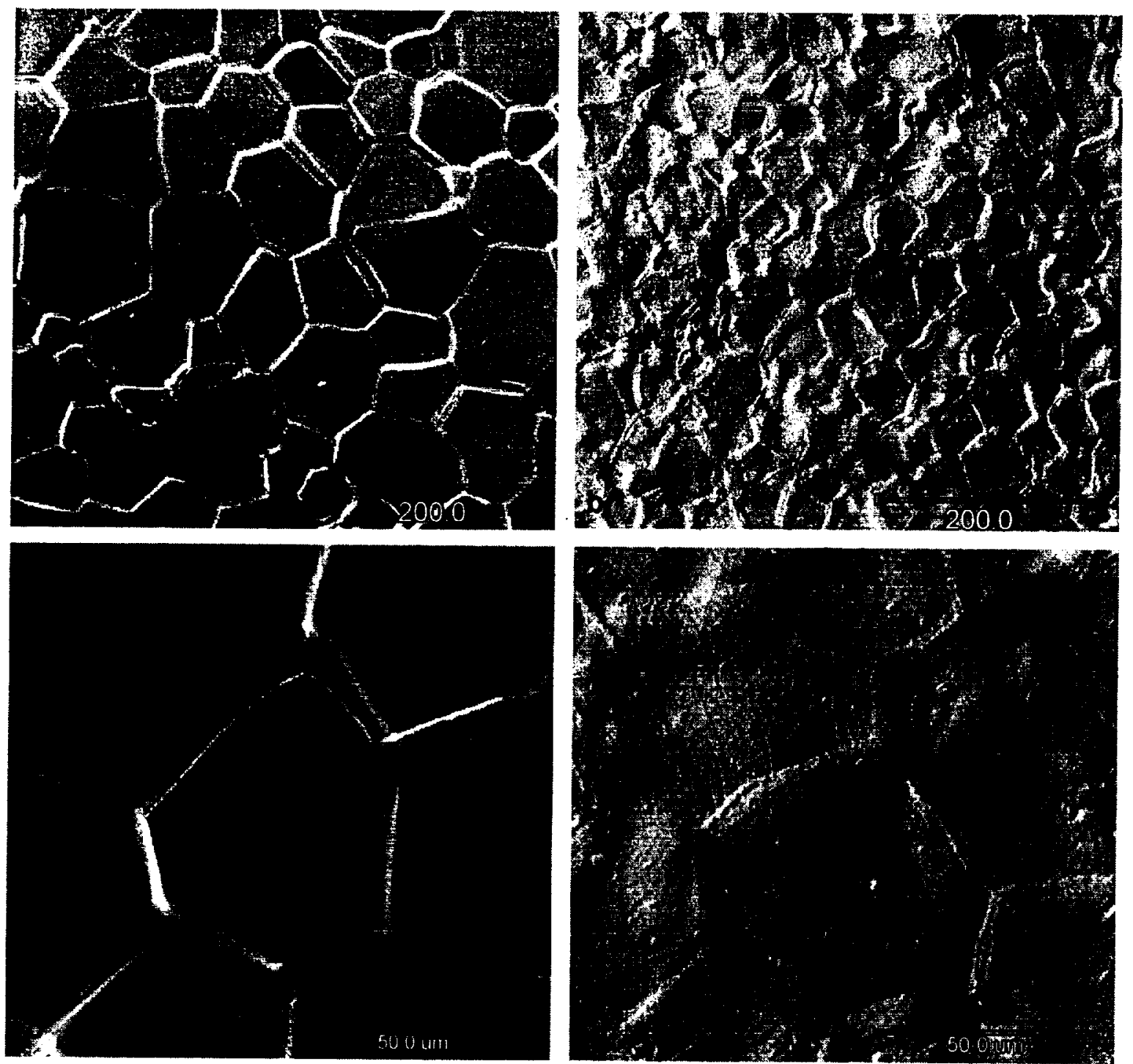

Figure 2. SEM micrographs of the surface of the $(\mathrm{a}, \mathrm{c})$ baseline and $(\mathrm{b}, \mathrm{d})$ Hf-containing bond coats.

The surface of the sample after the alumina grit blast and prior to top coat deposition is shown in Figure 4. The black regions in Figure $4 \mathrm{~b}$ were shown by EDS analysis to be alumina particles, presumably trapped and embedded during the grit blast. Although the ridges are very distinct after aluminizing, it is clear that the grit blast removes the ridge morphology.

Optical and SEM micrographs of the etched coating microstructures are shown in Figure 5. The outer portion of the coating is referred to as the $\beta$ phase ( $\mathrm{NiAl}$ or $\mathrm{CsCl}$ structure). The black particles clearly shown below the $\beta$ phase in Figure $5 \mathrm{~b}$ and over a larger area in Figure $5 \mathrm{~d}$ are alumina particles most likely embedded during the vapor hone surface cleaning prior to $\mathrm{Pt}$ electroplating. The region below the $\beta$ phase layer containing the bright particles in Figure $5 \mathrm{~b}$ and $\mathrm{d}$ is commonly referred to as the diffusion zone. The optical micrographs in Figures $5 \mathrm{a}$ and $\mathrm{c}$ show the large grain structure within the $\beta$ phase which is typical of aluminide coatings. The baseline coating also shows a row of columnar grains above the diffusion zone not present in the Hf-containing coating. The baseline coating in Figure $5 \mathrm{~b}$ is shown in the as-coated condition, 

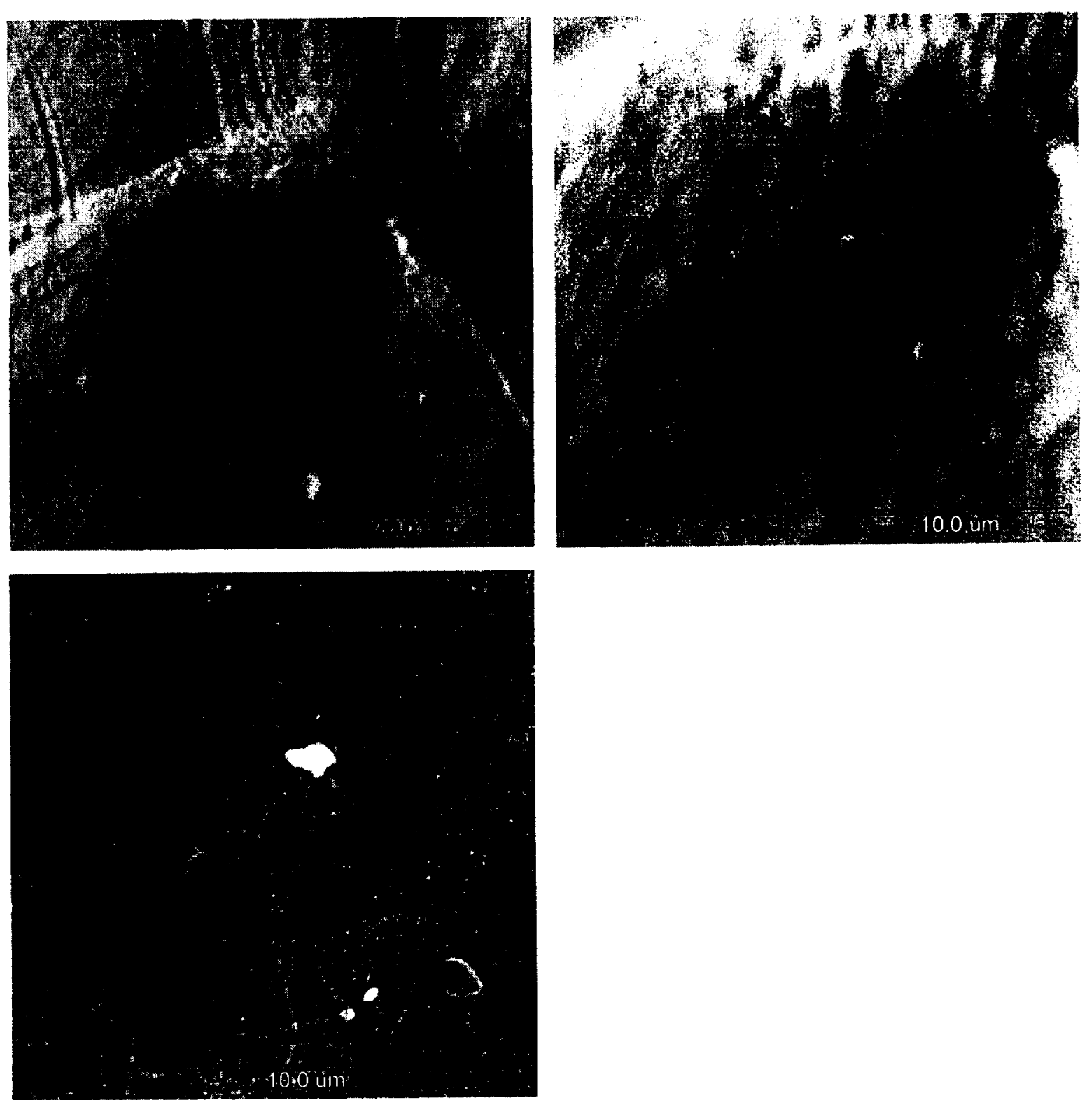

Figure 3. SEM micrographs of the surface of the ridge in Figure 2d. The arrow in Figure $2 \mathrm{~d}$ and above points to the same feature.

prior to the alumina grit blast, whereas the Hf-containing coating in Figure $5 \mathrm{~d}$ is shown after receiving the grit blast. The optical micrographs in Figure 5a show that the intersection of the grain boundaries with the surface are not directly located below the center of the ridges, similar to that observed previously [15].

The structure of the diffusion zone for both coatings is shown more clearly in Figure 6 . The bright particles are primarily topological close packed (TCP) phases rich in refractory elements (W, Re, $\mathrm{Cr}$ and Mo), as shown in the EDS spectra in Figure 7. Some bright particles associated with the TCP particles appear to be Ta carbides based on their EDS spectra (Figure 7). Concentration profiles through the coatings showed that the baseline coating contained more Pt than the Hfcontaining coating ( $\sim 33 \mathrm{wt} . \%$ vs. $\sim 23 \mathrm{wt} . \%$ at the center of the coating), although the reason for the higher level is unclear and possibly due to a slightly thicker Pt electroplate. The $\mathrm{Al}$ content of both coatings was similar, although the profile in the baseline coating was somewhat flatter with less gradient toward the substrate. The Hf concentration was low at the surface (less than $0.5 \mathrm{wt}$ 

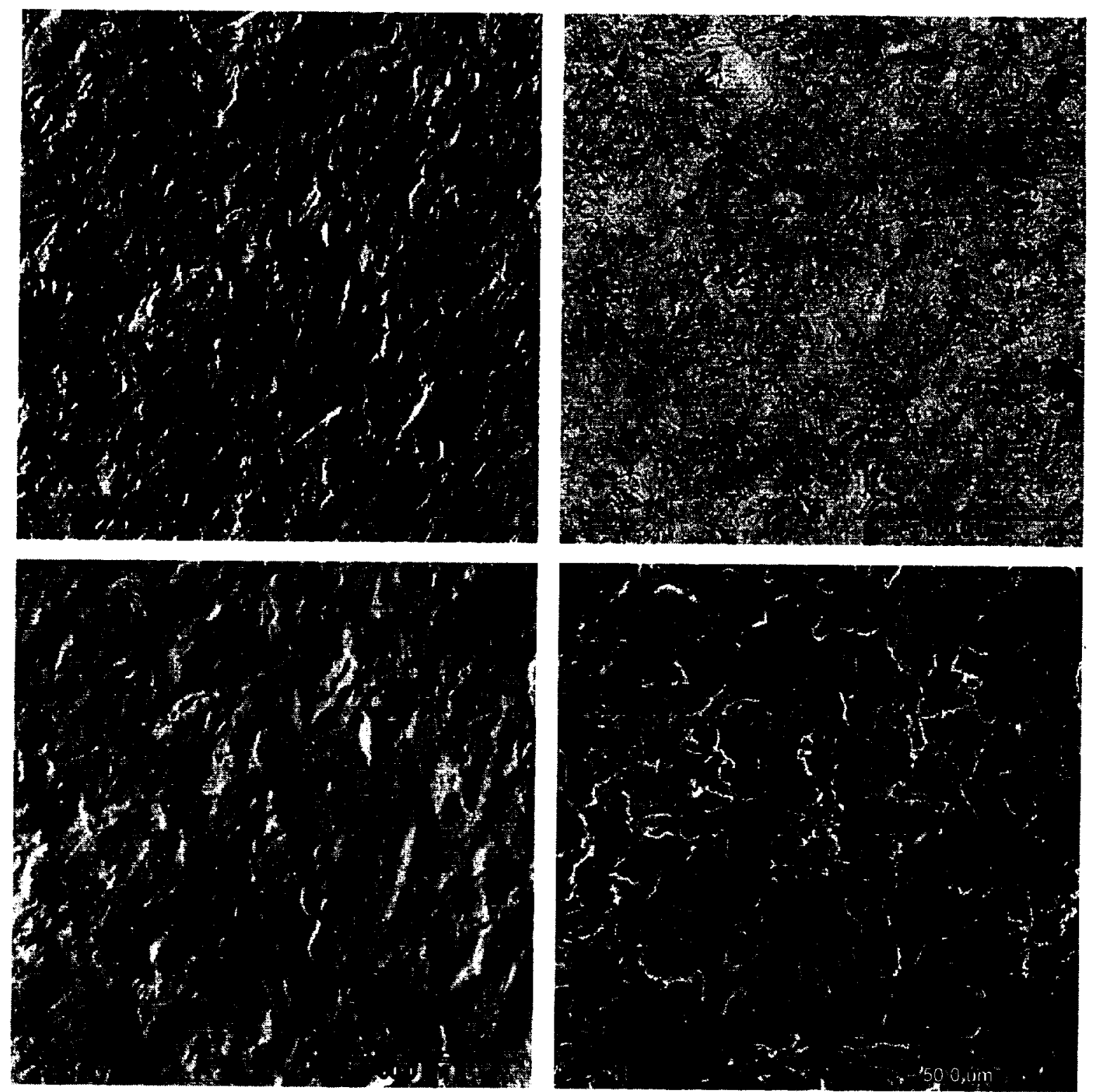

Figure 4. SEM micrographs of the surface of the Hf-containing bond coat after alumina grit blasting. (a) topo mode (b) BSE mode (c) higher mag of (a), topo mode (d) SEI mode

$\%$ ) but increased to the center of the coating to values greater than $3 \mathrm{wt} \%$. before trailing off within the diffusion zone.

\section{Post-test Coating Morphology and Microstructure}

Relative coating life ${ }^{\dagger}$ after furnace cycle testing for three baseline and nine Hf-containing samples is shown in Figure 8. The Hf-containing coatings have more than three times the life of the baseline coatings. A macrophoto of one of the baseline samples at failure is shown in Figure 9 a. Only a small amount of the ceramic top coat remained around the edges. The surface where the ceramic had spalled is shown at a higher magnification in Figure $9 \mathrm{~b}$ using the backscatter detector on the SEM. A magnified view of this region is shown in secondary electron image (SEI) and $\mathrm{BSE}$ in Figures $9 \mathrm{c}$ and $\mathrm{d}$ and at a higher magnification in Figure 10. Use of EDS clearly shows that the bright regions in the BSE images in Figures $9 \mathrm{~b}, 9 \mathrm{~d}$ and $10 \mathrm{~b}$ (labeled " $\mathrm{C}$ " in Figures 9d, 10b) are regions where the ceramic top coat and thermally grown alumina (TGO) have spalled

\footnotetext{
${ }^{\dagger}$ This data is subject to limited exclusive rights under NASA contract NAS3-26385.
} 

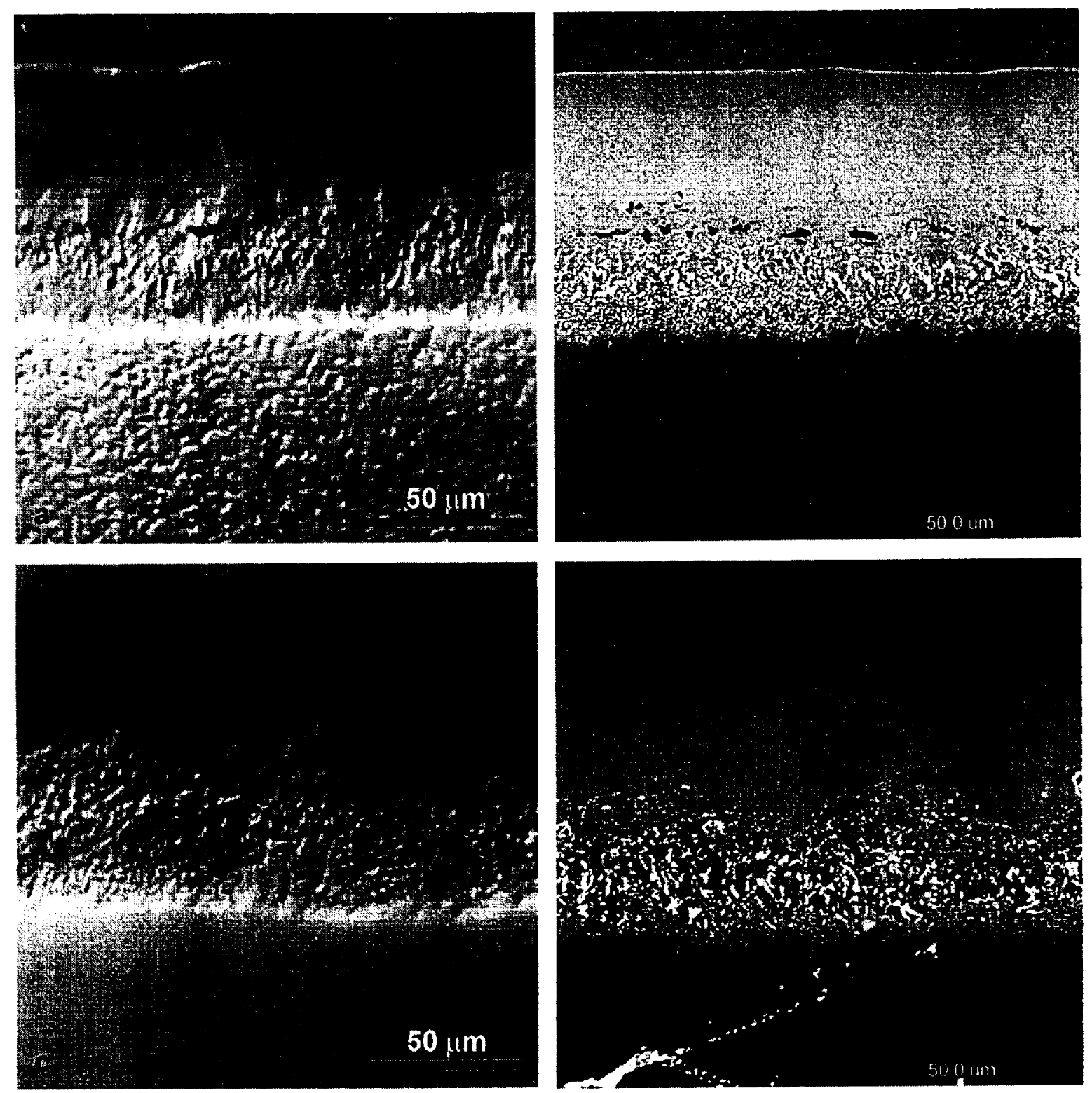

Figure 5. Optical and SEM micrographs of etched cross sections of the $(a, b)$ baseline prior to the alumina grit blast, and (c,d) Hf-containing bond coat after the alumina grit blast.

revealing the metallic bond coat. The darkest structure (" $\mathrm{A}$ ") in the BSE images is alumina. The structure with the intermediate gray shade (" $Z$ ") is remnants of the YSZ top coat. Hence, the bright regions in Figure $9 \mathrm{~b}$ indicate regions of loss of both the top coat and TGO exposing the surface of the coating. Oxide grain imprints from the alumina TGO are shown in Figure 10c. These imprints indicate that the alumina grains were on the order of slightly less than a micron in diameter. Lastly, Figure 10d shows that the exposed metallic coating surface is undulating with numerous hills and valleys. Etched cross sections of the coating and substrate are shown in Figure 11. Much of the $\beta$ phase remains in the coating although isolated regions of $\gamma^{\prime}$ have formed at the coating surface. Comparison of Figures $5 \mathrm{~b}$ and $11 \mathrm{~b}$ indicate that the width of the diffusion zone containing the TCP particles has increased.

Figure 12a shows a macrophoto of one of the Hf-containing disks at failure (i.e., after $3 x$ the baseline furnace cycles). More of the top coat remained on the surface when the disk was removed from the furnace test. BSE views of the surface where the top coat had spalled are shown 

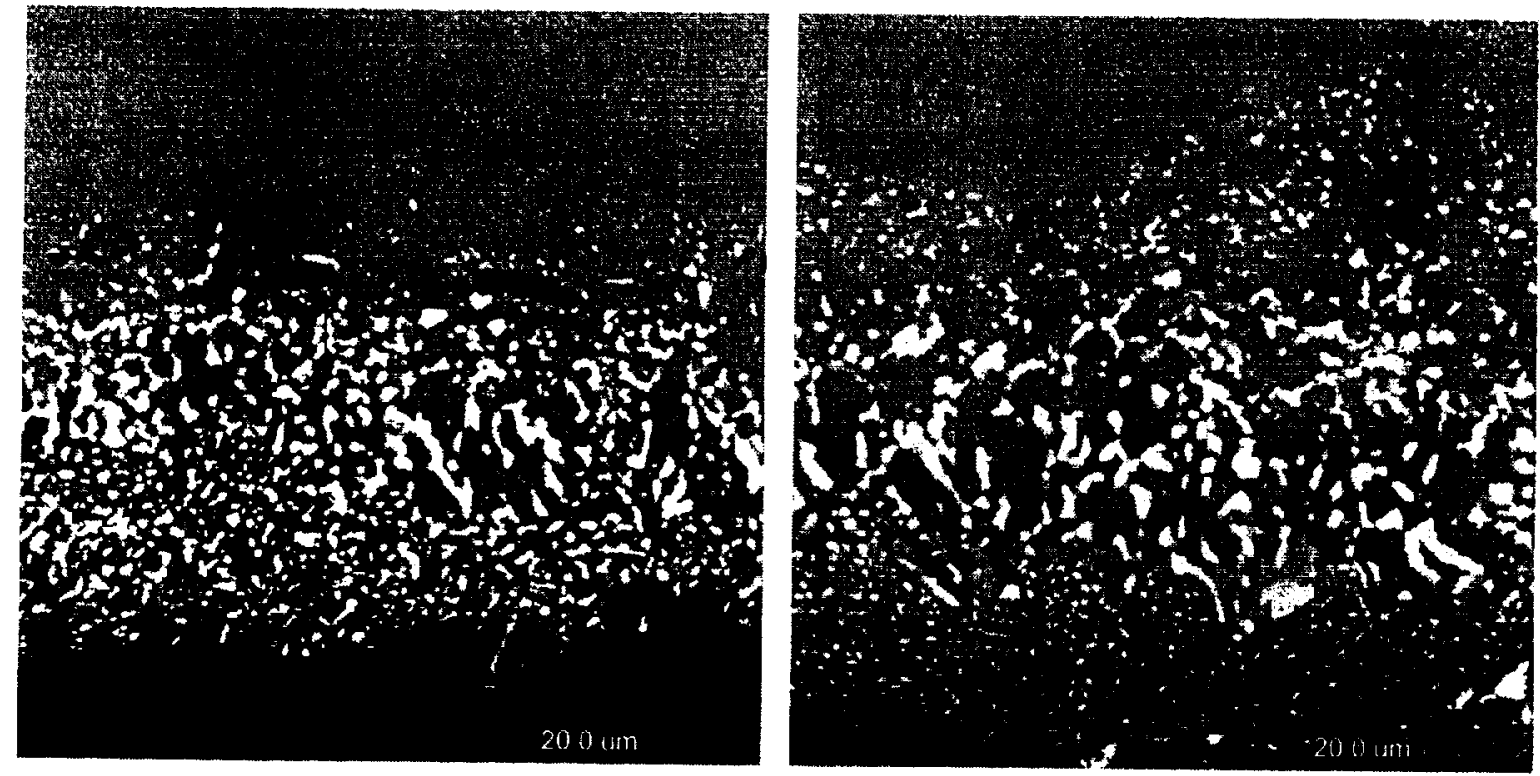

Figure 6. BSE SEM micrographs of the diffusion zone of the (a) baseline and (b) Hfcontaining bond coats.

in Figures 12b-d. On this disk, it was difficult to find bright regions where the TGO had spalled to the bare coating. Three small regions are indicated by arrows in Figure $12 \mathrm{~b}$ and magnified in Figures $12 \mathrm{c}$ and $\mathrm{d}$. The intermediate gray regions in Figure $12 \mathrm{~b}$ are regions where the YSZ top coat remained attached to the alumina TGO, as shown in Figure 13. Etched cross sections of the coating and substrate are shown in Figure 14. Many oxide stringers growing in from the surface are obvious. EDS of these oxides indicates a Hf oxide core surrounded by an alumina casing. This morphology of oxide stringers is commonly observed in oxidized alloys containing dilute reactive element additions.

\section{Discussion}

Clearly, the small Hf additions to the Pt-modified aluminide bond coats had a beneficial effect on the TBC life. Incorporation of the Hf did not greatly change the coating microstructure or morphology. The grain size appeared slightly smaller with the $\mathrm{Hf}$ addition, but similar to that of other aluminide and Pt-modified aluminide coatings [8,12,15-17]. The ridge morphology on the surface, and the region between the ridges, appeared somewhat different. However, since the surfaces are grit blasted before deposition of the top coat obliterating the ridge morphology, it does not seem likely that the slightly different surface morphology of $\mathrm{Hf}$-containing bond coats plays a significant role in extending the TBC life. Numerous investigators [8,12,15-17] attach significance to the role of grain boundaries and grain junctions as initiation sites for the spallation of the top coat. It is possible that the central oxide feature ringed with alumina in Figures 10a and $\mathrm{b}$ is an oxide-filled cavity similar to that observed by Gell $[8,15]$. Although not apparent in the micrographs in Figure 11, numerous oxide-filled cavities were observed in the polished cross sections on the baseline samples. It is likely that these cavities are associated with grain boundaries in the coating, also as observed previously $[8,15]$. However, in the Hf-containing coatings, the oxide stringers growing into the coating do not appear related to the grain boundaries. Stringers have been commonly observed when small reactive element additions are made to alloys and coatings [10] and have previously been observed with $\mathrm{Hf}$ additions to single crystal NiAl alloys [18]. Hence, the addition of Hf resulted in a abundance of oxide stringers much more numerous than the oxide-filled cavities at grain boundaries of the baseline coating. 


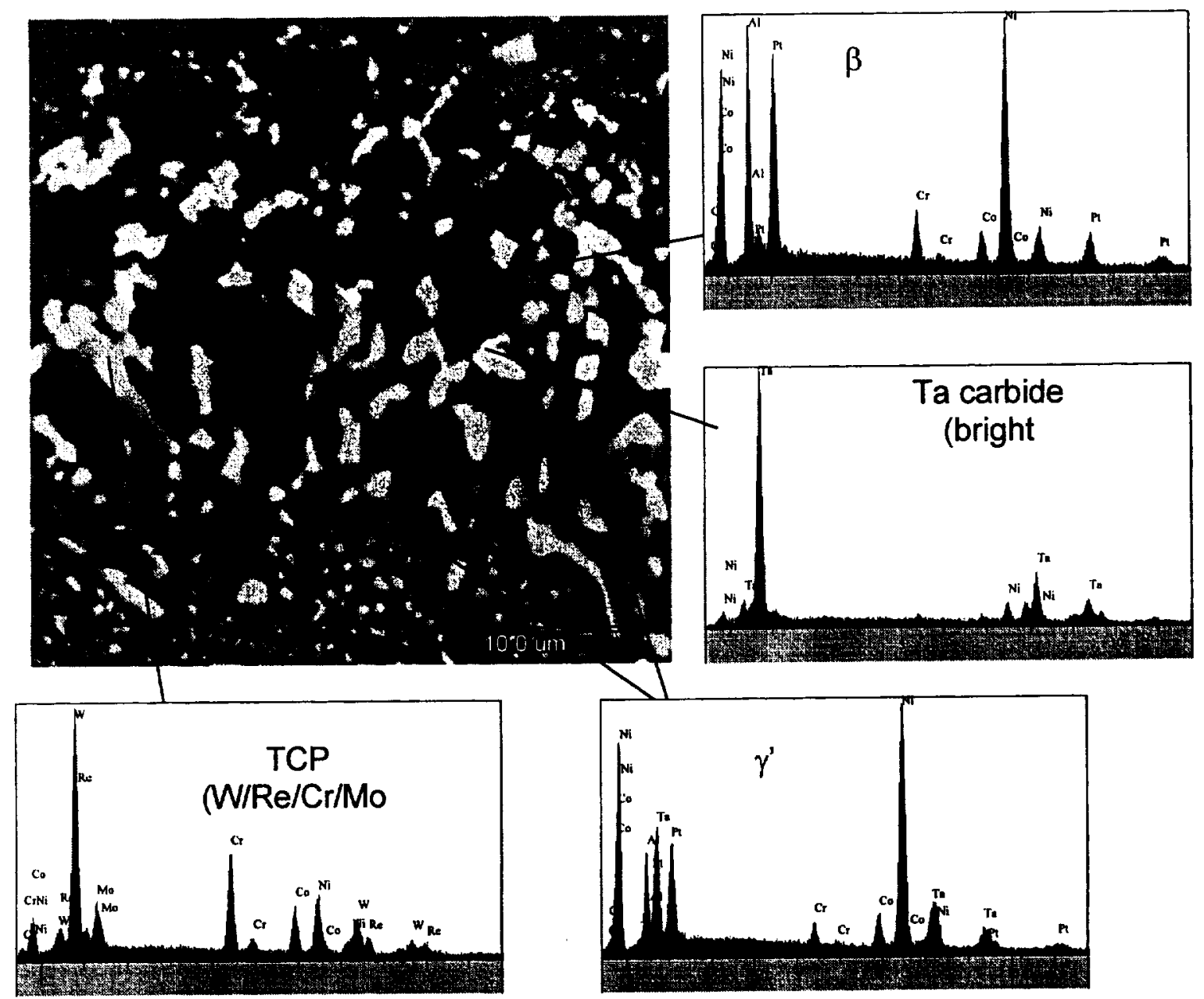

Figure 7. SEM micrograph and EDS spectra of the diffusion zone of the Hf-containing bond coat shown in Figure 6b.

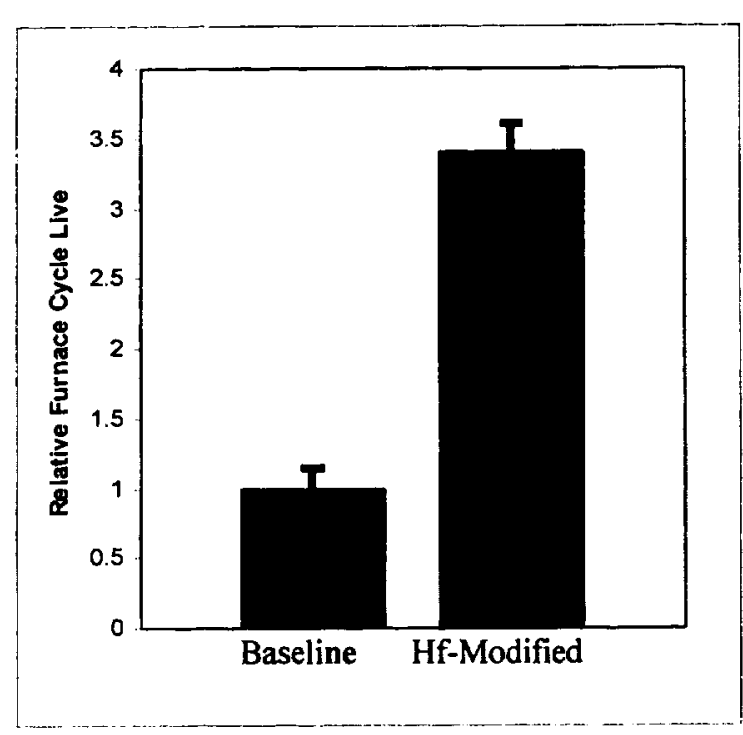

Figure 8. Average furnace cycle lives for the baseline and Hf-modified coatings. Standard deviations are shown by the error bars.
Two explanations for the beneficial effect of $\mathrm{Hf}$ are suggested. First, Hf appears to increase the adherence of the TGO alumina layer to the bond coat. This is clearly shown in a comparison of the surface morphologies in Figures $9 \mathrm{~b}$ and $12 \mathrm{~b}$. Typically, for EB-PVD TBC's, cracking and loss of the top coat occurs between the TGO and bond coat [1,2]. However, in the present baseline coating, less than $30 \%$ of the area in the spalled top coat region appears to have resulted in spalling to the bond coat surface (Figure $9 \mathrm{~b}$ ). Earlier work suggested that the addition of $\mathrm{Pt}$ to aluminide coatings improves the adherence of the alumina TGO layer during thermal cycling $[16,17]$. However, it is clear that there is even less spalling to the bond coat in the Hfcontaining coating (Figure 12b). A likely mechanism for this increased adherence is that the reactive element $(\mathrm{Hf})$ keeps sulfur from diffusing to the TGO-metal interface and 

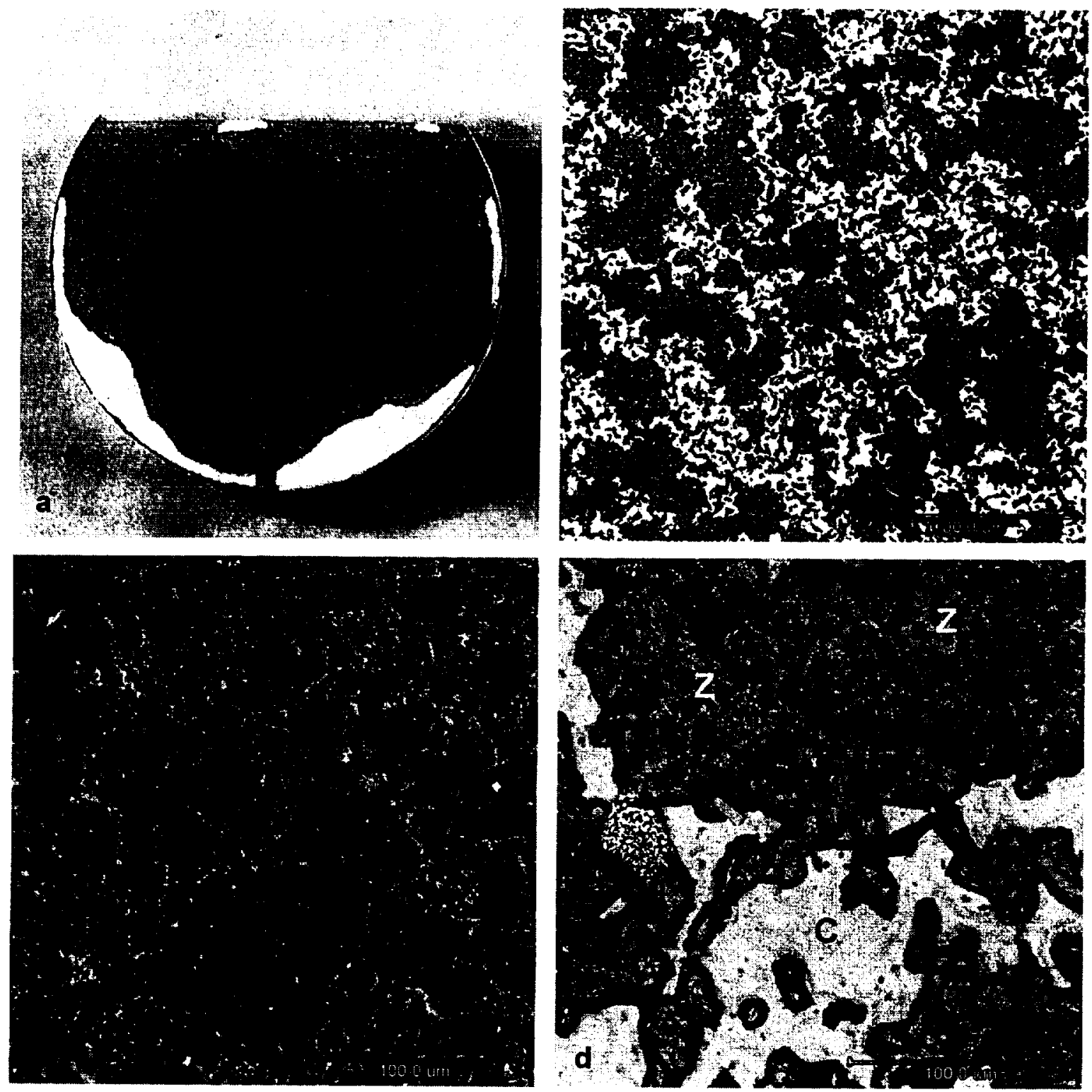

Figure 9. (a) Macrograph of the baseline disks at failure (b-d) SEM micrographs of the surface of the disk where the top coat has spalled. Light gray oxide in (d) is zirconia ( $Z$ ) and the bright regions are exposed metallic coating (C) (see Figure 10).

A second possible explanation for the beneficial effect of the $\mathrm{Hf}$ additions is that the resulting oxide stringers produce a "graded" layer between the bond coat and TGO. In this case, the coefficients of thermal expansion (CTE) varies continuously from the higher values of the metallic coating to the lower values of the alumina layer. This decrease in the mismatch of the CTE's produces less stress on cooling and thereby results in greater TBC lives. However, a similar peg morphology was produced in a Pt-modified aluminide coating by ion implanting either $\mathrm{Y}$ or Hf. [19]. Although YSZ top coats were not deposited, the Hf-rich pegs were associated with spallation of the oxide scale and considered detrimental to the adhesion of the scale. However, in regard to extending TBC life, it is possible that increased adhesion and a graded CTE contribute to the beneficial effect of $\mathrm{Hf}$ in the present coatings. 


\section{Conclusions}

Small Hf additions were incorporated into a CVD Pt aluminide bond coat on single crystal RENÉ N5 substrates. Standard YSZ top coats were subsequently deposited by EB-PVD. In furnace testing, the Hf-containing bond coats increased the TBC life by slightly more than three times that of a baseline coating containing no Hf. Scanning electron microscopy of the spalled surfaces indicated that the presence of the Hf increased the adherence of the thermally grown alumina to the $\mathrm{Pt}$ aluminide bond coat. The presence of the $\mathrm{Hf}$ also resulted in numerous oxide pegs growing into the coating from the thermally grown alumina.
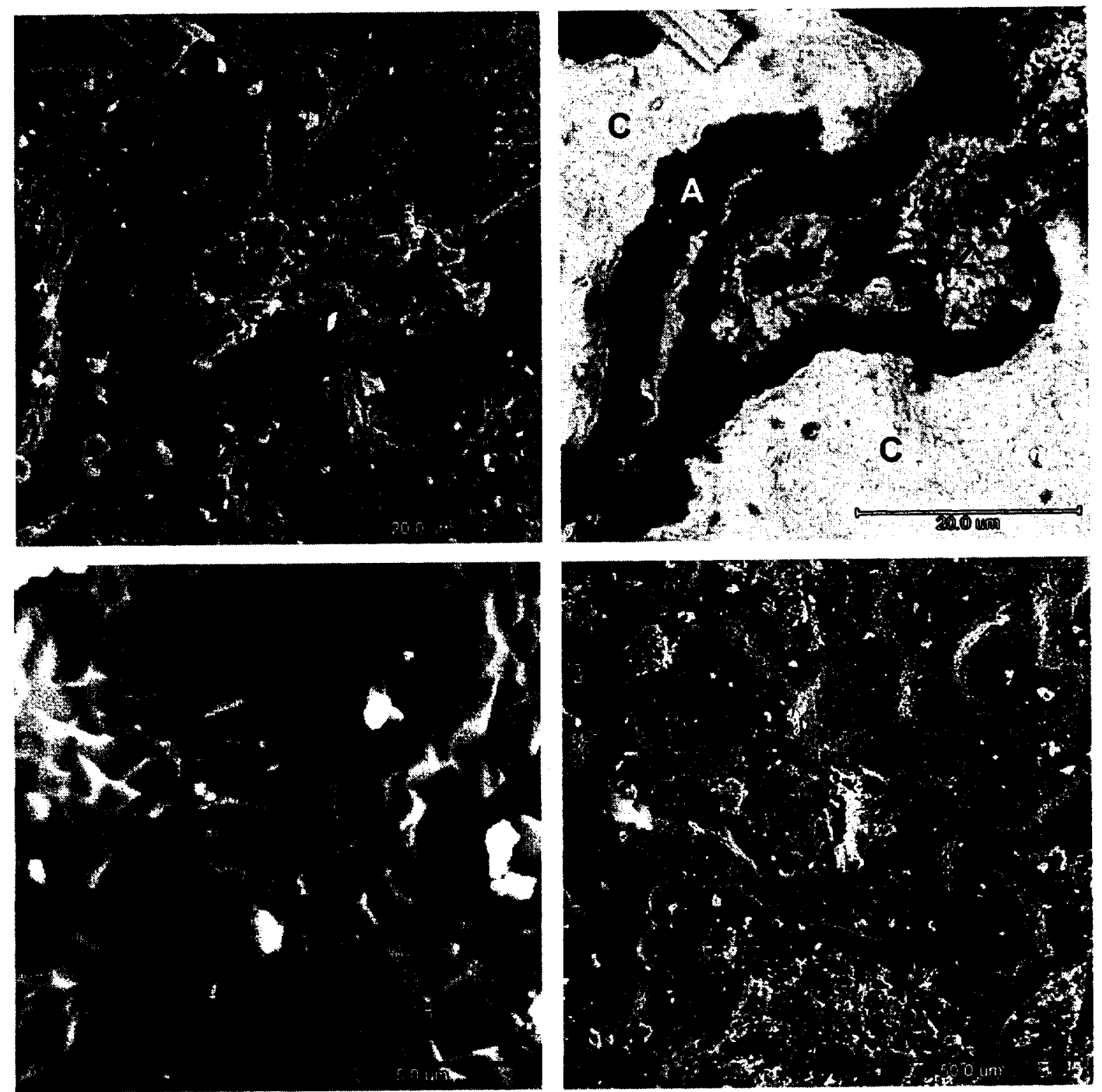

Figure 10. SEM micrographs of the surface of the baseline coating shown in Figure 9, (a,c,d SEI mode, (b) BSE mode. Dark oxide in (b) is alumina (A), light gray oxide is zirconia (Z), brightest region is exposed metallic coating (C). 


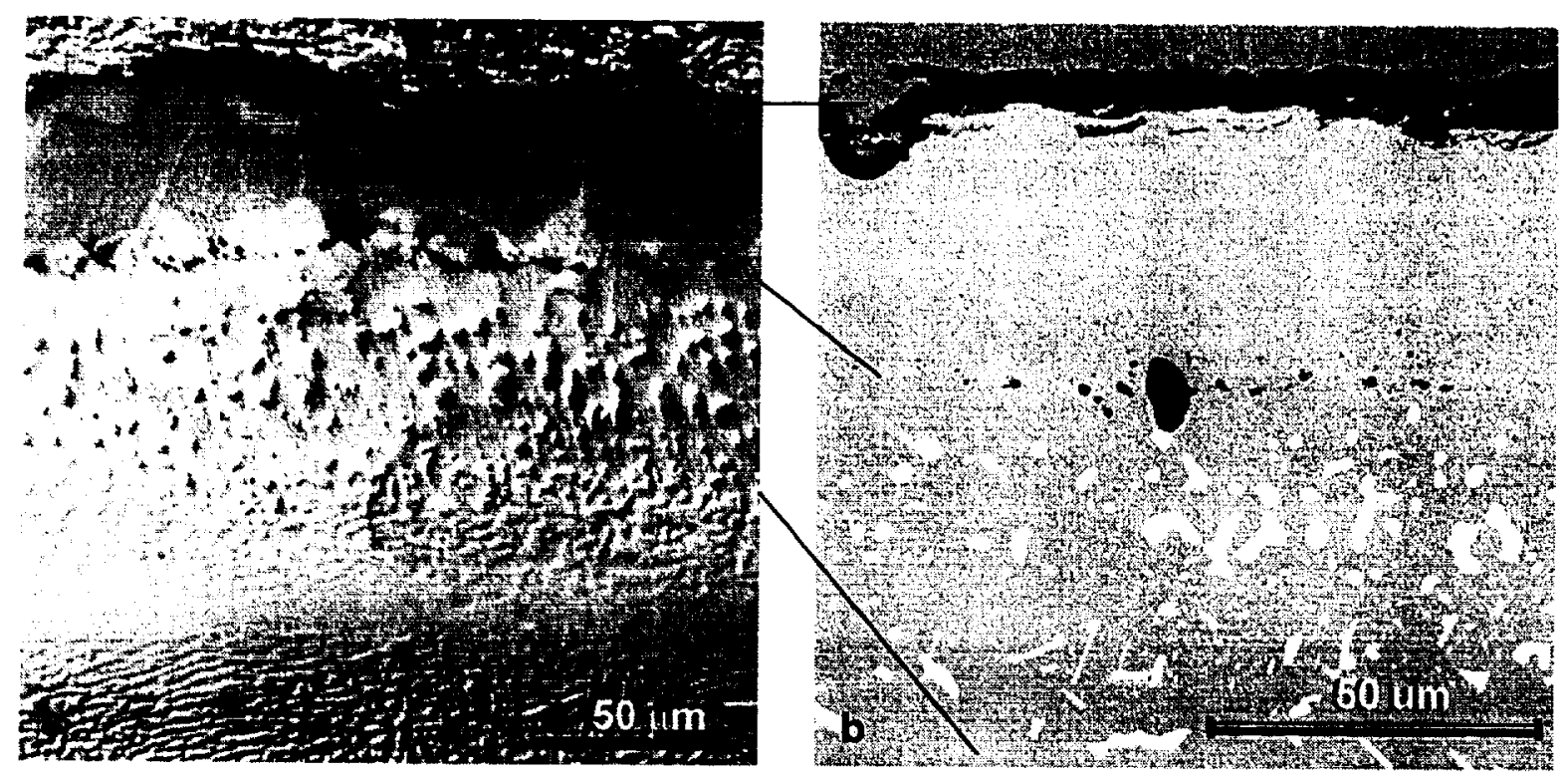

Figure 11. (a) Optical and (b) SEM micrographs of the baseline coating at failure. The lines indicate approximately similar locations within the coating.

\section{Acknowledgements}

This work was supported under the Enabling Propulsion Materials Program (EPM) and Ultra Efficient Engine Technologies (UEET) programs at the NASA Glenn Research Center. Two of the authors (BN and JW) acknowledge useful discussions with Ram Darolia and Tony Maricocchi of GE Aircraft Engines.

\section{References}

1. S.M. Meier, D.M. Nissley, K.D. Sheffler and T.A. Cruse, "Thermal Barrier Coating Life Prediction Model Development," Trans. ASME, 114, (1992) 258-264.

2. A. Maricocchi, A. Bartz, and D.J. Wortman, "PVD TBC Experience on GE Aircraft Engines," in Proceedings 1995 Thermal Barrier Workshop, W.J. Brindley, ed., (NASA CP 3312 , Washington, DC, 1995), 79-89.

3. F.O. Soechting, "A Design Perspective on Thermal Barrier Coatings," in Proceedings 1995 Thermal Barrier Workshop, W.J. Brindley, ed., (NASA CP 3312, Washington, DC, 1995), 116.

4. J.T. DeMasi-Marcin and D. Gupta, Protective Coatings in the Gas Turbine Engine," Surf. Coat. Technol., 68/69 (1994) 1-9.

5. B.M. Warnes and D.C. Punola, "Clean diffusion Coatings by Chemical Vapor Deposition," Surf. Coat. Technol., 94/95 (1997) 1-6.

6. H.M. Tawancy et al., "Thermal Stability of a Platinum Aluminide Coating on Nickel-Based Superalloys," J. Mat. Sci., 27 (1992) 6463-6474. 

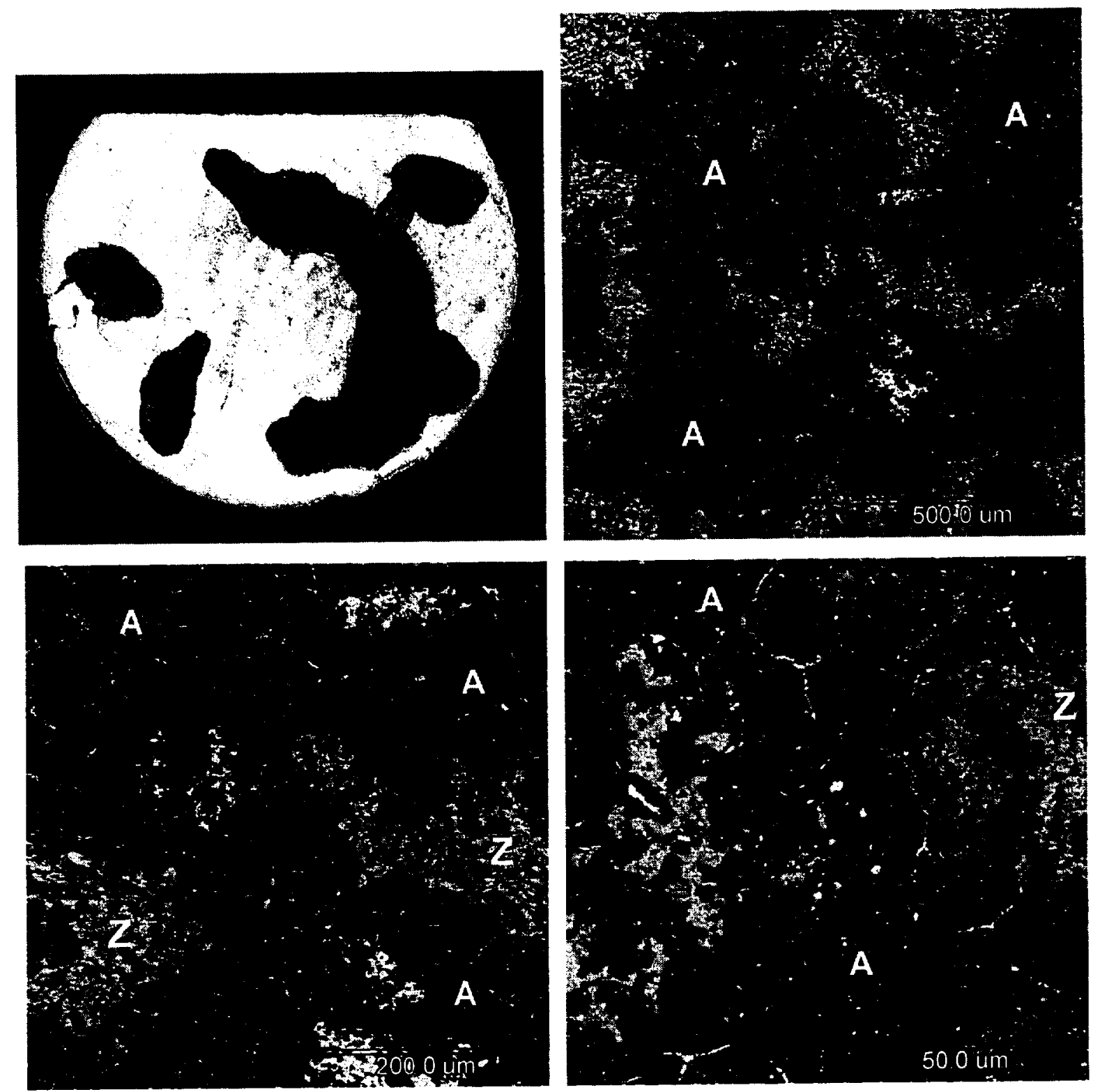

Figure 12. (a) Optical macrograph and (b-d) BSE SEM micrographs of the surface of the $\mathrm{Hf}$-containing bond coat at failure. Arrows indicate regions of exposed bond coat. Dark oxide is alumina (A), light gray oxide is zirconia $(\mathrm{Z})$.

7. C.H. Lee et al., "Phase Transformation and Bond Coat Oxidation Behavior of Plasma-Sprayed Zirconia Thermal Barrier Coatings," Surf. Coat. Technol. 124 (2000) 1-12.

8. M. Gell, et al., "Bond Strength, Bond Stress and Spallation Mechanisms of Thermal Barrier Coatings," Surf. Coat. Technol., 120-121 (1999) 53-60.

9. N. Czech et al., "Studies of the Bond Coat Oxidation and Phase Structure of TBCs," Surf. Coat. Technol., 113 (1999) 157-164.

10. J. Stringer, "The Reactive Element Effect in High-Temperature Corrosion," Mater. Sci. Eng., A120, (1989) 129-137. 


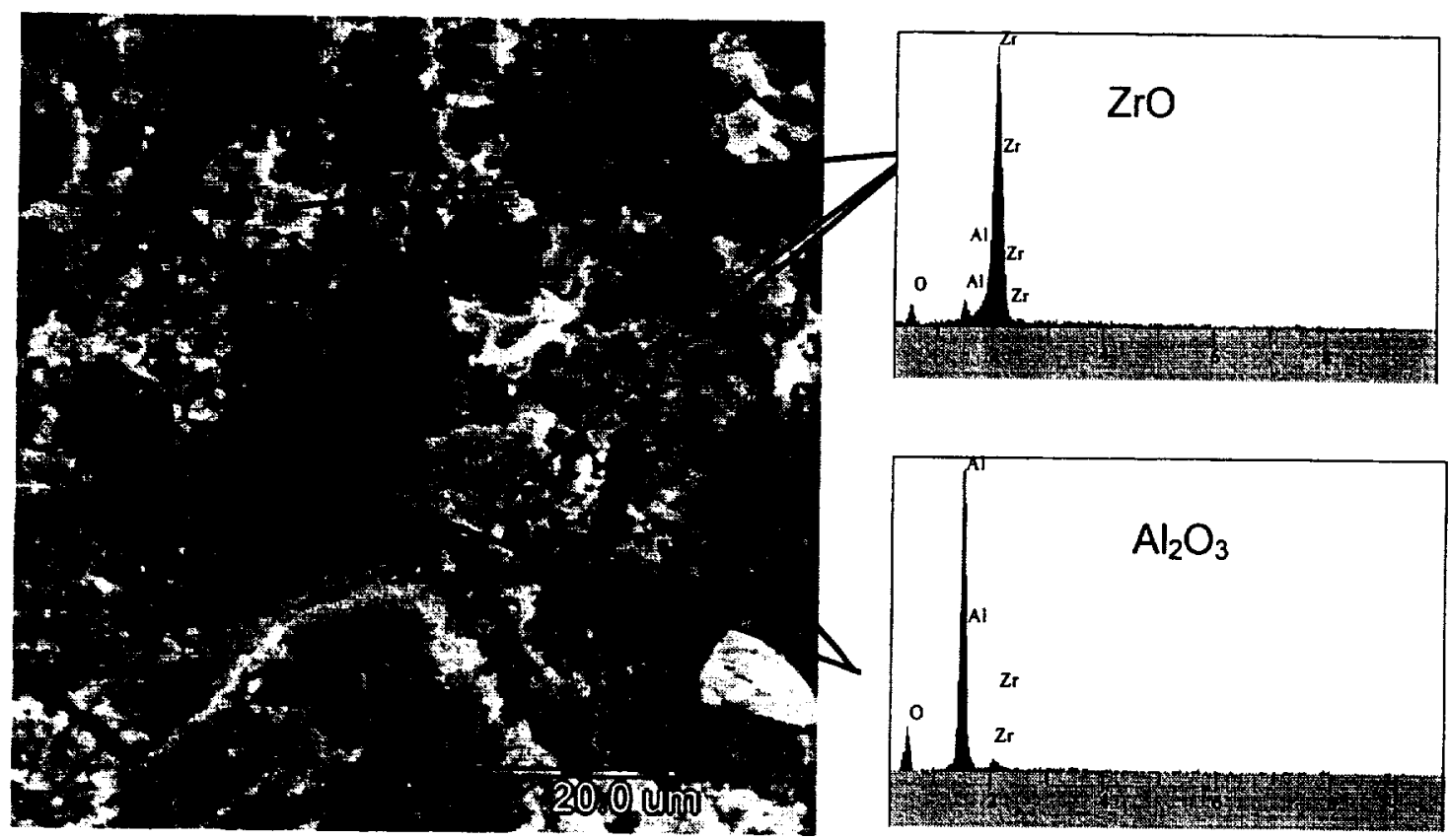

Figure 13. SEM micrograph and EDS spectra showing pieces of the zirconia top coat attached to the TGO alumina.

11. W.Y. Lee and G.Y. Kim, Kinetic Considerations for Processing a Diffusion NiAl Coating Uniformly Doped with a Reactive Element by Chemical Vapor Deposition," Elevated Temperature Coatings: Science and Technology III, J.M. Hampikian and N.B. Dahotre, eds., (TMS, Warrendale, PA, 1999), 149-160.

12. W.Y. Lee et al., "Effects of Sulfur Impurity on the Scale Adhesion Behavior of a Desulfurized Ni-based Superalloy Aluminized by Chemical Vapor Deposition" Met. Mater. Trans., 29A (1998) 833-841.

13. W.P. Allen and N.S. Bornstein, Effect of Sulfur Activity on the Oxidation Resistance of Aluminide Coatings, in Elevated Temperature Coatings: Science and Technology I, N.B. Dahotre, J.M. Hampikian and J.J. Stiglich, eds., (TMS, Warrendale, PA, 1995), 193-202.

14. J.L. Smialek, "Oxidation Resistance and Critical Sulfur content of Single Crystal Superalloys," Trans. ASME, 120 (1998) 370-374.

15. M. Gell et al., "Mechanism of Spallation in Platinum Aluminide/Electron Beam Physical Vapor-Deposited Thermal Barrier Coatings," Met. Mater. Trans., 30A (1999) 427-435.

16. Y. Zhang et al., "Synthesis and Cyclic Oxidation Behavior of a (Ni,Pt) Al Coating on a Desulfurized Ni-based Superalloy" Metal. Mater. Trans., 30A (1999) 2679-2687.

17. J.A. Haynes et al., in Elevated Temperature Coatings: Science and Technology III, J.M. Hampikian and N.B. Dahotre, eds., (TMS, Warrendale, PA, 1999), 185-196.

18. J.A. Nesbitt, C.A. Barrett amd R. Darolia, "Cyclic Oxidation of Single-Crystal NiAl-X Alloys," in High Temperature Corrosion and Materials Chemistry, M. McNallan et al., eds., (Electrochem. Soc. Proceedings Volume 99-38, 1999), 192-203. 


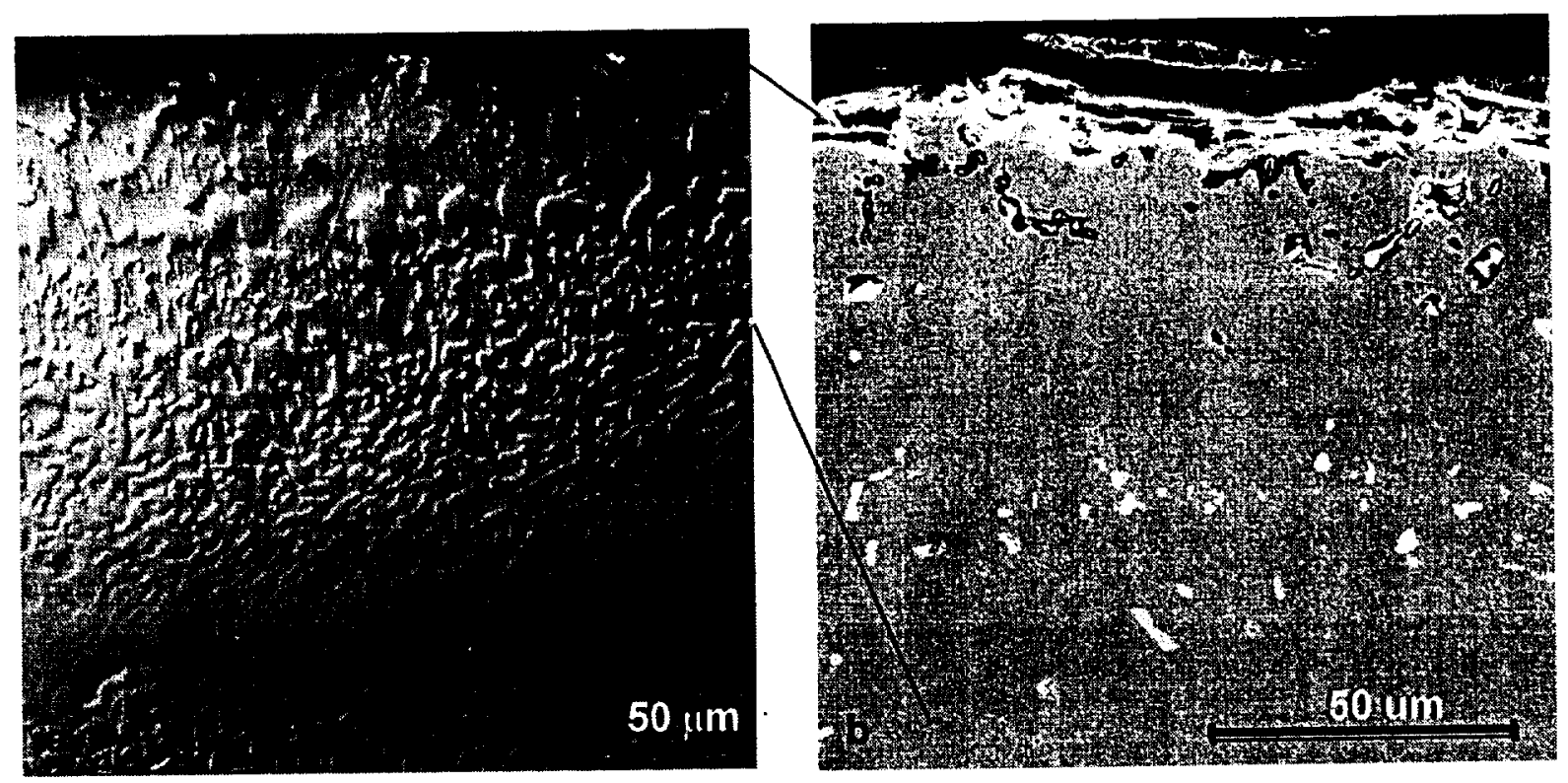

Figure 14. (a) Optical and (b) SEM micrographs of the Hf-containing coating at failure. The lines indicate approximately similar locations within the coating.

19. G. Fisher et al., "The Effects of Active Element Additions on the Oxidation Performance of a Platinum Aluminide Coating at $1100^{\circ} \mathrm{C}$," Surf. Coat. Technol., 110 (1998) 24-30. 
